\title{
Formas de organizar a Educação Física no ensino primário: memórias de professoras da Escola Giuseppe Garibaldi, Caxias do Sul/RS (1974-1985)
}

Ways of organizing Physical Education in primary education: memories of teachers of the Giuseppe Garibaldi School, Caxias do Sul/RS (1974-1985)

Formas de organizar la Educación Física en la enseñanza primaria: recuerdos de profesoras de la Escuela Giuseppe Garibaldi, Caxias do Sul/RS (1974-1985)

\author{
Cristian Giacomoni \\ Universidade de Caxias do Sul (Brasil) \\ http://lattes.cnpq.br/1565948131391927 \\ https://orcid.org/0000-0002-9598-2750 \\ cgiacomoni@ucs.br \\ José Edimar de Souza \\ Universidade de Caxias do Sul (Brasil) \\ http://lattes.cnpq.br/3693254783408309 \\ https://orcid.org/0000-0003-1104-9347 \\ profedimar@gmail.com
}

\section{Resumo}

Este estudo analisa narrativas de duas professoras primárias da Escola Giuseppe Garibaldi, cujas memórias auxiliaram na compreensão das formas de organização das aulas de Educação Física. Pretendemos recompor as possíveis histórias do ensino neste local, desde a fundação da escola em 1974 até 1985, ano do término do regime civil militar. A perspectiva teórica é da História Cultural, e utiliza a metodologia da História Oral, mediante as memórias das professoras Jacira Koff Saraiva e Jaqueline Gedoz Vita. Para Halbwachs (2006), as possíveis narrativas históricas de um contexto são constituídas pelos compilados de fatos que se destacam, e que são selecionados pelas memórias dos sujeitos. Essas memórias estão interligadas aos convívios sociais e podem ser influenciadas pelos diversos âmbitos em que o sujeito está imbricado. As evidencias apontam que as aulas de Educação Física eram organizadas a partir dos conhecimentos docentes, fundamentados pelas brincadeiras e esportes, porém sem a concepção competitivista.

Palavras chave: Educação Física. Ensino primário. Memórias. 


\begin{abstract}
This study analyzes narratives of two primary teachers of the Giuseppe Garibaldi School, whose memories helped to understand the ways of organizing Physical Education classes. We intend to recompose the possible stories of teaching in this place, from the foundation of the school in 1974 until 1985, year of the end of the military civilian regime. The perspective is from Cultural History, and uses the methodology of Oral History, through the memories of the teachers Jacira Koff Saraiva and Jaqueline Gedoz Vita. For Halbwachs (2006), the possible historical narratives of a context are constituted by compiled facts that stand out, and which are selected by the memories of the subjects. These memories are intertwined with social relationships and can be influenced by the various scopes in which the subject is imbricated. The evidence indicates that the classes of Physical Education were organized from the teachers' knowledge, based on the games and sports, but without the competitive conception.
\end{abstract}

Keyworks: Physical Education. Primary education. Memories.

\title{
Resumen
}

Este estudio analiza narrativas de dos maestras primarias de la Escuela Giuseppe Garibaldi, cuyos recuerdos ayudaron en la comprensión de las formas de organización de las clases de Educación Física. Pretendemos recomponer las posibles historias de la enseñanza en este lugar, desde la fundación de la escuela en 1974 hasta 1985, año del término del régimen civil militar. La perspectiva teórica es de la Historia Cultural, y utiliza la metodología de la Historia Oral, mediante las memorias de las profesoras Jacira Koff Saraiva y Jaqueline Gedoz Vita. Para Halbwachs (2006), las posibles narrativas históricas de un contexto son constituidas por los compilados de hechos que se destacan, y que son seleccionados por las memorias de los sujetos. Estas memorias están interconectadas a las convivencias sociales y pueden ser influenciadas por los diversos ámbitos en que el sujeto está imbricado. Las evidencias apuntan que las clases de Educación Física eran organizadas a partir de los conocimientos docentes, fundamentados por las bromas y los deportes, pero sin la concepción competitivista.

Palabras clave: Educación Física. Enseñanza primaria. Recuerdos. 


\section{Considerações iniciais}

Jogar bola, praticar exercícios, cantar e ainda realizar brincadeiras talvez seja uma das lembranças de muitos alunos sobre as aulas de Educação Física nas primeiras séries do ensino primário. Nesse sentido, o estudo tem como objetivo analisar memórias de professoras de uma escola de Caxias do Sul/RS sobre o modo de organizar as aulas de Educação Física, entre 1974 a 1985.

O município de Caxias do Sul está situado na região nordeste do Estado do Rio Grande do Sul (RS), conforme Figura 1. Atualmente o município possui uma área total de $1.638,34 \mathrm{~km}^{2}$, com aproximadamente 500.000 habitantes, a cerca de $127 \mathrm{~km}$ da capital Porto Alegre. Possui suas divisas municipais: ao norte com São Marcos, Campestre da Serra e Monte Alegre dos Campos, ao sul com Vale Real, Nova Petrópolis, Gramado e Canela, a leste São Francisco de Paula e a oeste Flores da Cunha e Farroupilha (CAXIAS DO SUL, 2017).

Figura 1: Caxias do Sul em destaque no mapa do Estado do Rio Grande do Sul

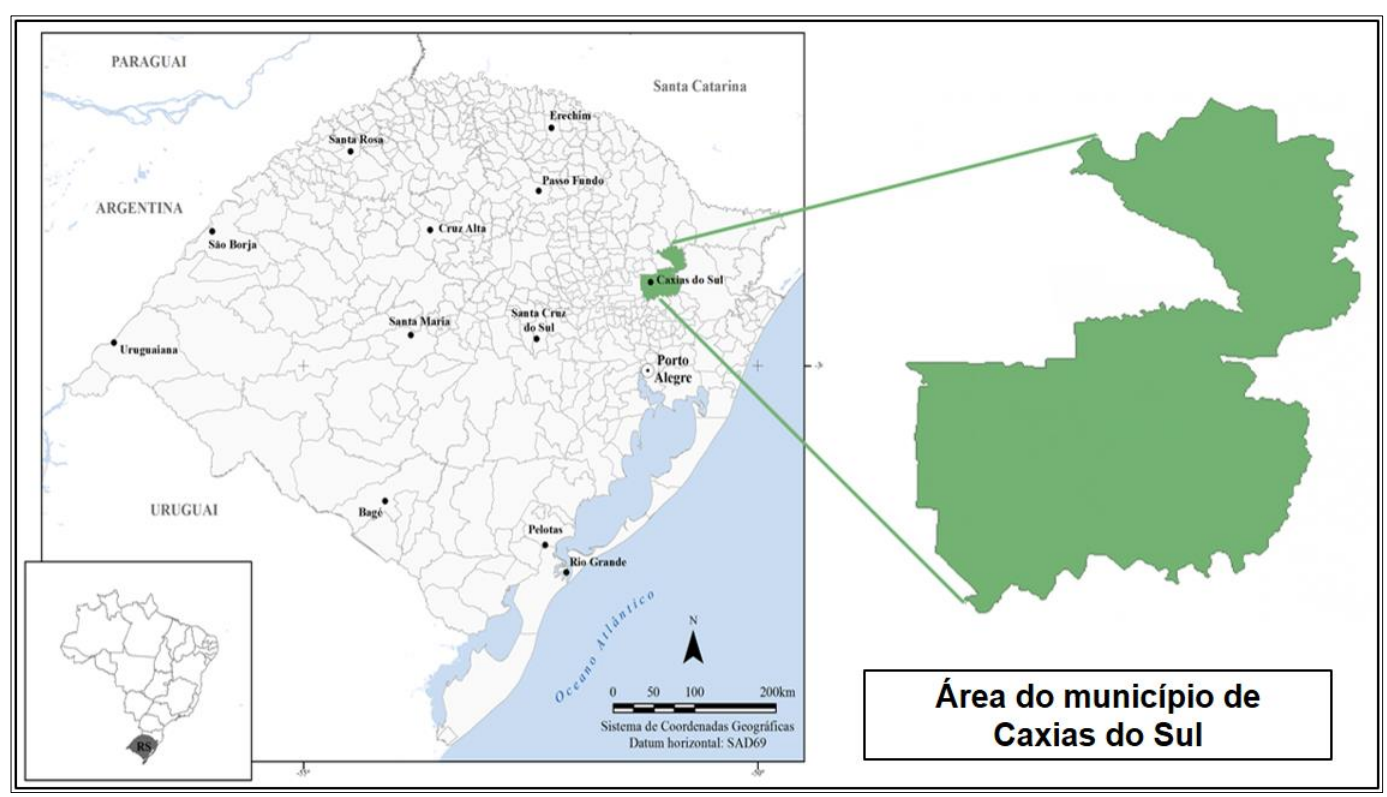

Fonte: RIO GRANDE DO SUL (2019). Adaptado a partir de Divisão Geopolítica do Estado do Rio Grande do Sul, Fundação Estadual de Economia e Estatística.

Os processos de implementação da Escola Giuseppe Garibaldi (EGG) ${ }^{1}$ aconteceram no início do ano de 1974, em uma reunião realizada na residência do Sr. João Neves, entre a Associação de Moradores do Bairro Cristo Redentor ${ }^{2}$ e o prefeito Mario Bernardino Ramos. Nesta reunião foram apresentadas as demandas da comunidade, com destaque às reivindicações para a construção de uma escola. O prefeito designou a secretária de educação,

\footnotetext{
${ }^{1}$ Optamos em identificá-la como Escola Giuseppe Garibaldi, visto que a instituição possuiu alterações nas suas denominações ao longo do recorte temporal adotado. Também justificamos esta escolha ao compreender o conceito de escola segundo Nóvoa (1992), ou seja, como uma instituição fundamentada num sistema organizado e complexo de comportamentos humanos, advindos das diversas interações e ações do cotidiano escolar que transpassam também as barreiras das próprias instituições e seus processos de escolarização.

2 No ano de 1974, o Bairro Cristo Redentor, como é denominado atualmente, era popularmente conhecido como Bairro Boa Vista. Esse nome foi dado pelos moradores ao afirmarem que o bairro possuía uma "vista bonita" com muitas árvores nativas e campos verdes, e também devido a uma suposta rivalidade atribuída a um bairro vizinho chamado de Bela Vista (CAXIAS DO SUL, 1986). Neste estudo optamos em mencioná-lo apenas como Bairro Cristo Redentor, pois o Bairro Boa Vista permanece com esta denominação oficial até o ano de 1977 (CAXIAS DO SUL, 1977).
} 
Santina Barp Amorim, como responsável pela resolução dos trâmites legais e organização para a abertura e funcionamento da escola (EMEFGG, 1974).

Para agilizar todos os processos burocráticos, visto a urgência exposta pela comunidade, foi sugerido pelo poder público alugar o piso inferior da residência do Sr. João Neves, no entanto, o espaço necessitaria de algumas adaptações físicas para receber os alunos. Isso foi possível devido ao auxílio do Sr. Ernesto Romualdo Rissi, presidente da Associação de Moradores, e de alguns membros da comunidade que realizaram o trabalho (EMEFGG, 1974; JACIRA, 2017).

Para Luchese (2014, p. 147), apesar de uma pesquisa possuir caráter local e investigar os processos educativos relacionados à Educação Física primária ${ }^{3}$ produzidos em uma instituição específica, muitos destes processos estão conectados "[...] pelas redes de contextos e relações em diferentes âmbitos espaciais: local, regional, nacional e internacional", seja também por meio das relações, das práticas e/ou das culturas humanas.

A pesquisa foi composta por duas professoras primárias oriundas de períodos e formações pedagógicas distintas. A primeira professora, Jacira Koff Saraiva, formou-se pelo curso normalista no final dos anos 60 , foi uma das articuladoras para a fundação da escola em 1974, assim como acumulou as funções de diretora e professora neste mesmo ano. A segunda professora, Jaqueline Gedoz Vita, obteve sua formação pelo curso de magistério no início dos anos 80, ingressando na escola no ano de 1982 para lecionar ao ensino primário. Cabe ressaltar que ambas as professoras receberam uma formação generalista no que diz respeito à Educação Física (JACIRA, 2017; JAQUELINE, 2017).

O recorte temporal adotado inicia-se em 1974 com a constituição da EGG, e finalizase em 1985 com a eleição indireta do Presidente Tancredo Neves, em 15 de janeiro de 1985 (MENDONÇA, 2005). Este período do regime civil militar brasileiro foi caracterizado pela utilização da Educação Física nas escolas, principalmente através do esporte e de atividades cívicas, como plano formativo voltado ao ideal de nação grande, em desenvolvimento industrial, social e econômico, ao controle e alienação social e de sujeitos e corpos disciplinados. Conforme Oliveira (2002), a Educação Física escolar, intermediada pela Lei ${ }^{\circ}$ $5.692 / 71^{4}$ em seu artigo $7^{\circ}$, tornou-se obrigatória em todos os níveis escolares. Essa obrigatoriedade foi regulamentada pelo Decreto ${ }^{\circ}$ 69.450/71, que determinou padrões para as aulas de Educação Física no interior escolar.

Deste modo, a Educação Física no âmbito escolar estruturou-se pela corrente formativa dos esportes, em muitos momentos se relacionou com o ensino de caráter tecnicista, e ainda possuiu competências ligadas às atividades cívicas. Este panorama apresentado visava à formação de um sujeito disciplinado e com boas aptidões ao mercado de trabalho. Assim, procuramos cotejar o movimento nacional ocorrido com a Educação Física no ensino primário com o âmbito local, destacando a formação generalista das professoras primárias, os espaços físicos adaptados para aulas e a escassez de materiais didáticos para organização de outras possibilidades educativas.

\section{Perspectivas teóricas e metodológicas}

As narrativas históricas tornam-se plausíveis e verossímeis a partir de escolhas e lentes teóricas que auxiliam os pesquisadores a elucidar os seus objetivos. Deste modo, os pressupostos teóricos mobilizados estão apoiados pela História Cultural, pelas possibilidades narrativas de diferentes trajetórias de vida, de instituições, de grupos sociais sob diferentes formas e conceitos.

\footnotetext{
3 Após a promulgação da LDBEN/71, o ensino primário passou a denominar-se de ensino de $1^{\circ}$ grau, com duração de oito anos. Porém, nesta investigação iremos direcionar atenções às primeiras etapas da formação educacional, ou seja, para $1^{\mathrm{a}}$ a $4^{\mathrm{a}}$ série. Assim, optamos em mencionar tudo como ensino primário.

${ }^{4}$ Denominada de Lei de Diretrizes e Bases da Educação Nacional, ou LDBEN.
} 
Para Souza (2011), a História Cultural permite aos pesquisadores analisar os processos de escolarização, as experiências do cotidiano e os contextos de suas constituições em determinados espaços e tempos. Também justificamos esta escolha teórica por "[...] identificar o modo como em diferentes lugares e momentos uma determinada realidade social é construída, pensada, dada a ler" (CHARTIER, 1988, p. 16-17). Um contributo relevante da História Cultural foram as novas possibilidades na utilização de fontes, como fotografias, documentos ordinários ${ }^{5}$, cadernos, diários, assim como a oralidade e o uso das memórias enquanto documentos (BURKE, 2008).

A partir do exposto, procuramos evidenciar as formas de organização e de desenvolvimento das aulas e práticas da Educação Física primária pelas professoras Jacira e Jaqueline, permeando a narrativa entre o contexto histórico do período e as lembranças sobre o cotidiano escolar. Para Halbwachs (2006), as memórias estão interligadas aos convívios sociais, e suas "construções" ocorrem mediante as relações entre os sujeitos ou os grupos dos quais fazem parte, e que podem ser resultados das influências as quais estão submetidas, como, por exemplo, a família, a escola, a sociedade, o governo, as relações de poder e suas próprias regras. Deste ponto de vista, as memórias se evidenciam tanto de forma individual como coletiva.

Ademais, segundo Hobsbawm (1998), as memórias são constituídas através de uma seleção individual das infinitas memórias que são lembradas ou capazes de serem lembradas, e podem proporcionar encontros de um passado com o presente, estruturando-se pelas " [...] vivências, espaços e lugares, tempos, pessoas, sentimentos, percepções/sensações, objetos, sons e silêncios, aromas e sabores, texturas, formas" (STEPHANOU; BASTOS, 2011, p. 420). As rememorações dos sujeitos podem evidenciar elementos, indícios, subsídios que outros documentos não possibilitam, auxiliando os pesquisadores na compreensão das formas como as professoras primárias organizavam as aulas de Educação Física e, sobretudo, as representações das práticas escolares daqueles espaços e tempos.

As práticas escolares, conforme Vidal e Schwartz (2010), são engendradas pelas ações criativas e ativas dos sujeitos que influenciam as maneiras como compreendem suas identidades, experiências e percepções de mundo. São produzidas no âmbito escolar, nas relações entre os sujeitos em diferentes estados de desenvolvimento, compostas por regras, relações, valores, princípios sociais e culturais, assim como nas relações diretas e indiretas dos grupos sociais que fazem parte, pois são essas "[...] as práticas que visam a fazer reconhecer uma identidade social, exibir uma maneira própria de estar no mundo" (CHARTIER, 1988, p. 23).

Do ponto de vista metodológico, foi adotada a História Oral, pelas perspectivas de produção de uma "versão e visão" histórica, por intermédio das narrativas dos sujeitos sobre as práticas, culturas, conjunturas, cotidianos e suas relações (LOZANO, 2005). Desta forma, optamos pela realização de entrevistas semiestruturadas, que após transcritas, organizadas e categorizadas, se tornaram documentos empíricos passíveis de análises, interpretações e contextualizações. Segundo Ferreira e Amado (2005), a História Oral é um método científico que organiza e estabelece critérios e procedimentos, nas diversas formas de trabalhar as entrevistas. A memória é o subsídio essencial para a utilização desta metodologia, pois

$\mathrm{Na}$ história oral, o objeto de estudo do historiador é recuperado e recriado por intermédio a memória dos informantes; a instancia da memória passa, necessariamente, a nortear as reflexões históricas, acarretando desdobramentos teóricos e metodológicos importantes [...] (FERREIRA; AMADO, 2005, p. 15).

\footnotetext{
${ }^{5}$ Conforme Mignot e Cunha (2006, p. 41), os documentos denominados de “ordinários” preservam “[...] histórias individuais e familiares, trazem marcas da escolarização e permitem pensar distintas interpretações da escola e da educação".
} 
A História Oral valoriza as memórias dos sujeitos entrevistados, com relevância para aqueles que vivenciaram os acontecimentos que atualmente são o objeto de pesquisa. No contexto vivenciado pelas entrevistadas, também foram adotados os pressupostos de dimensões da memória, neste caso o "esquecimento condicionado". Como Grazziotin (2008, p. 62) esclarece, o esquecimento de memórias pode ser percebido em sociedades,

[...] submetidas a regimes totalitários [...] que tudo fez para provocar a amnésia forçada de uma sociedade, levada a esquecer o que não é desejado num determinado tempo, implantando outra memória, condicionada a um regime de verdade intencionalmente criado.

A partir deste princípio, as professoras teoricamente deveriam se precaver acerca dos conteúdos, saberes e ideais escolares que organizavam e desenvolviam nos processos de escolarização. Cabe ressaltar que, apesar de adotarmos este pressuposto de dimensão da memória - "esquecimento condicionado" -, as entrevistadas não evidenciaram ou mencionaram nenhum tipo de repressão ou censura por parte do poder público, e relataram ter "liberdade" para organizar e desenvolver suas aulas.

Em referência às entrevistas ${ }^{6}$, foram elaboradas dez questões norteadoras, porém sempre que suscitavam novas dúvidas ou questionamentos eram realizadas outras perguntas, constituindo um formato semiestruturado de entrevista. Para Manzini (2012, p. 156), a entrevista semiestruturada "[...] tem como característica um roteiro com perguntas abertas e é indicada para estudar um fenômeno com uma população específica [...]". A seleção das professoras teve como objetivo aproximar "[...] aqueles que participaram, viveram, presenciaram ou se inteiraram de ocorrências ou situações ligadas ao tema e que possam fornecer depoimentos significativos" (ALBERTI, 2013, p. 40).

A primeira entrevistada ${ }^{7}$, professora Jacira Koff Saraiva rememorou a fundação escolar, os primeiros espaços físicos, a organização e o desenvolvimento das aulas. Jaqueline Gedoz Vita, segunda entrevistada, ingressou em 1982 nas novas instalações escolares que foram inauguradas em 1976, o que a possibilitou compreender como ocorreram as melhorias físicas, a ampliação dos materiais e as mudanças na organização e desenvolvimento das aulas. Desta forma, foi possível obter indícios sobre ambos os espaços e os tempos da EGG e as diferenças de organização e desenvolvimento dessas aulas.

Deste modo, o artigo foi organizado em cinco partes, além da introdução. A primeira parte apresenta os pressupostos teóricos e metodológicos adotados para este estudo. Num segundo momento contextualiza o período do regime civil militar e os processos educativos relacionados às aulas e às práticas de Educação Física nos âmbitos nacional e local. Na sequência realiza-se a estruturação do contexto mediante as memórias, que permitiram recompor uma das possíveis histórias sobre as aulas e as práticas de Educação Física na EGG, assim como as considerações finais.

\footnotetext{
${ }^{6}$ Ressaltamos que as narrativas utilizadas no estudo foram autorizadas mediante o Termo de Consentimento Livre e Esclarecido (TCLE). O TCLE foi elaborado a partir do modelo criado e aplicado por Souza (2015), com algumas alterações, como a inclusão da Resolução no 510 de 07 de abril de 2016, sobre Pesquisas em Ciências Humanas e Sociais. Foi esclarecido às entrevistadas os riscos envolvidos, como cansaço ou constrangimento no decorrer da entrevista. Todas optaram em divulgar seus nomes.

${ }^{7}$ As entrevistas foram realizadas nas residências das professoras com agendamento prévio por telefone, por meio do qual foram informadas com antecedência sobre o tema da entrevista. Além disso, solicitamos que tomassem nota sobre qualquer lembrança de suas aulas de Educação Física no ensino primário, e as orientamos a pesquisar por qualquer documento daquele período. As entrevistas foram gravadas com aparelho digital, tiveram duração média de 40 a 60 minutos e cerca de 10 a 15 páginas após transcritas. A realização das entrevistas seguiu os pressupostos de Alberti (2013).
} 


\section{Contexto nacional e local: formas de organizar a educação física no ensino primário}

Nesta seção, apresentamos o contexto educacional vivenciado em âmbito nacional e local e suas relações com as formas de organizar e desenvolver as aulas de Educação Física no ensino primário. As pesquisas que se debruçam sobre determinadas instituições escolares em particular são relevantes para o campo da história da educação brasileira, no momento em que essas instituições integram sistemas escolares mais amplos e estão permeadas pelos valores de cada período histórico (BUFFA, 2002).

As instituições de ensino deste período histórico eram constituídas, em grande parte, pelos denominados grupos escolares. Segundo Bencostta (2005), este modelo de instituição escolar diferenciava-se dos demais ${ }^{8}$, pela criação da seriação do ensino primário em quatro anos, em que cada série possui seu próprio professor, com a ordenação dos saberes escolares inseridos nos programas de ensino. Foi nos grupos escolares que emergiram novas maneiras de organização do ensino, caracterizados pela:

[...] racionalização e a padronização do ensino, a divisão do trabalho docente, a classificação dos alunos, o estabelecimento de exames, a necessidade de prédios próprios com a consequente constituição da escola como lugar, o estabelecimento de programas amplos e enciclopédicos, a profissionalização do magistério, novos procedimentos de ensino, uma nova cultura escolar (SOUZA, 1998, p. 49-50).

A educação primária brasileira, durante o regime civil militar, foi fundamentada por metodologias de ensino tecnicistas direcionadas a formação para o mercado de trabalho. O objetivo tecnicista estava voltado para a potencialização da economia do país, por meio da qualificação da mão de obra, sem pretensões de formação crítica dos sujeitos. O governo almejava atingir seus objetivos de industrialização, qualificação da mão de obra e crescimento econômico intermediado também pelas reformas das legislações educacionais (FURLAN, 2013).

Nesse sentido, a formação educacional preterida possuía como principal objetivo a preparação ao mercado de trabalho, "[...] e não de desenvolvimento das habilidades individuais mais amplas e diversificadas, formando assim uma grande massa manipulada pelas ordens políticas e econômicas" (FURLAN, 2013, p. 2). Esses valores morais, normas sociais e educacionais foram implementados na década de 1960 e perduraram durante o regime, ao utilizar a "[...] repressão e o controle ideológico político do ensino, com objetivo de eliminar toda e qualquer forma de crítica para consolidar seu projeto de dominação" (MACIEL et al., 2016, p. 6).

No município de Caxias do Sul, os grupos escolares também constituíam a grande parcela das instituições educativas, principalmente entre a década de 70 e metade dos anos 80, quando começam a surgir novas maneiras de organizar o ensino. A formação educativa primária esteve pautada sob três bases: a leitura, a escrita e a aritmética (DALLA VECCHIA; HERÉDIA; RAMOS, 2008). Estas instituições locais também possuíam as mesmas

\footnotetext{
8 Além dos grupos escolares, existiam outros modelos, como as Escolas Isoladas e as Escolas Reunidas. Conforme Souza (2015), as Escolas Isoladas eram caracterizadas, em grande parte, por ter um professor que lecionava todas as disciplinas, independente do grau de adiantamento dos alunos. Localizavam-se tanto no meio urbano como no rural, geralmente funcionando em um prédio improvisado ou na casa do próprio professor, e não eram denominadas de isoladas pelo fato de possuírem classes autônomas, mas sim pelo seu funcionamento de forma unitária. Escolas Reunidas foi a denominação para o agrupamento das Escolas Isoladas em um mesmo edifício. Uma das finalidades desse modelo escolar era classificar os alunos pelo seu nível intelectual e unir dois ou mais anos em apenas uma classe (GIL; CALDEIRA, 2011).
} 
características dos demais educandários brasileiros, no entanto, apresentavam singularidades, como o sentimento de pertencimento a uma "cultura italiana", por meio da religiosidade expressada pelo catolicismo e pela assiduidade escolar vinculada à disciplina para formação de um cidadão responsável (DALLA VECCHIA; HERÉDIA; RAMOS, 1998).

Sobre o catolicismo, Jacira e Jaqueline (2017) destacaram em suas narrativas, que nas salas de aula da EGG, comumente havia um crucifixo fixado sobre o quadro negro, e que existiam momentos no início das aulas em que se realizavam orações. Também ressaltam que a assiduidade e a frequência nas aulas eram relacionadas às obrigações escolares e às atividades avaliativas. Conforme Iwaya (2000), alguns ritos foram característicos e permaneceram ao longo dos anos nas instituições primárias brasileiras, principalmente a formação de filas antes de entrar nas salas de aula e o controle sobre os horários para cada atividade, elementos que compõem partes de uma cultura escolar destas instituições primárias.

Em relação à Educação Física escolar, no âmbito nacional durante os anos 70, podemos conjecturar que eram cumpridas as diretrizes do poder público, fundamentadas pelo desenvolvimento social e econômico, por meio do ensino tecnicista. Desta forma, ao utilizar

[...] a tecnificação das práticas corporais representaria melhoria das condições da força de trabalho, no sentido de torná-la mais eficiente e eficaz no processo de produção; a racionalidade e o planejamento da economia da educação conformavam então, as políticas públicas e, consequentemente, as práticas escolares, deixando pouco ou nenhum espaço para a intervenção dos sujeitos na história (OLIVEIRA, 2001, p. 36).

A interferência do governo nacional sobre as diretrizes educacionais tornou a Educação Física escolar praticamente restrita às práticas esportivas. Segundo Oliveira (2002), esta interferência pode ter sido influenciada em função de dois fatores. O esporte apresentouse como uma prática normatizada e institucionalizada que seria capaz de reproduzir as pretensões de controle, e que não abriria possibilidades educacionais tanto aos professores quanto aos alunos. O segundo ponto, de acordo com o autor, decorre da afirmação do esporte como um fenômeno cultural de massa a nível mundial.

A utilização dos esportes na organização e desenvolvimento das aulas de Educação Física durante este período ficou denominada como corrente competitivista de ensino, ao preconizar a técnica e o desempenho. As práticas escolares nas aulas de Educação Física possuíam como principal fundamento o ensino e desenvolvimento da técnica, do gesto e da repetição esportiva, reduzindo as possibilidades de práticas corporais a algumas poucas técnicas reproduzidas de maneiras mecanizadas (OLIVEIRA, 2001).

Para Soares et al. (2009), a corrente competitivista nas escolas também contribuiu para restringir as práticas essencialmente aos esportes. As ginásticas ${ }^{9}$, o atletismo ${ }^{10}$ dentre outras atividades, foram postas em segundo plano, o que caracterizou as aulas em práticas formativas esportivas com intuito de desempenho. Ainda, de acordo com os autores, as relações sociais das aulas de Educação Física foram diretamente impactadas pela utilização dos esportes, o que proporcionou a constituição de uma dicotomia evidenciada pelo "professor-técnico" e o "aluno-atleta".

No âmbito municipal, durante os anos 70, as aulas eram organizadas e desenvolvidas principalmente pelas brincadeiras vinculadas à pratica do lazer. Os esportes, futebol e

\footnotetext{
${ }^{9}$ As ginásticas na escola são compreendidas pelos exercícios com intuito de melhora dos aspectos físicos, mas também pelos “[...] vários tipos de manifestações, tais como danças, expressões folclóricas e jogos, apresentados através de atividades livres e criativas, sempre fundamentadas em atividades ginásticas” (SANTOS, 2001, p. 23).

${ }^{10}$ Quando nos referimos ao termo atletismo neste estudo, relacionamos às práticas de corridas, saltos e arremessos.
} 
voleibol, mantiveram seu lugar de destaque nas aulas, porém eram realizados de forma adaptada, na medida em que os grupos escolares da região não possuíam espaços físicos adequados e haviam poucos materiais didáticos (GIACOMONI, 2018).

Ao avançar para a década de 80 , emergem novos movimentos contrários às concepções tecnicistas de ensino, visto que o regime civil militar termina com a eleição indireta do Presidente Tancredo Neves, em 15 de janeiro de 1985. Paulatinamente, os brasileiros começam a ter maiores aberturas nos âmbitos sociais, políticos e educacionais no país (MENDONÇA, 2005). Essas aberturas tinham como intuito "[...] à transição de um modelo político ditatorial para um modelo de redemocratização" (SILVA; BEZERRA; SANTOS, 2017, p. 2).

A nova proposta de modelo educacional orientada pela redemocratização brasileira tinha duas premissas fundamentais: promover a educação crítica do aluno por meio da pluralização pedagógica e atender todos em idade escolar, preferencialmente às demandas das classes mais populares (RICCI, 2003). Para Zientarski e Pereira (2009), esse movimento de redemocratização da educação brasileira pressupôs também a democratização do conhecimento, do acesso, da garantia de permanência, da gestão, da qualidade e da gratuidade, o que na prática não aconteceu dessa forma.

De forma gradual, acompanhando as mudanças educacionais, a organização e o desenvolvimento das aulas de Educação Física começam a mudar. Conforme Bracht (1999), a Educação Física no ensino primário começa a interagir com os campos das ciências sociais e humanas, através de uma análise crítica do modelo competitivista e tecnicista. O principal ponto questionado era a função social que a Educação Física ocupava na educação primária. Foram mediante discussões das políticas educacionais que a psicomotricidade ${ }^{11}$ foi inserida e utilizada na década de 80 , pretendendo possibilitar aos alunos

[...] oportunidades de experiências de movimento de modo a garantir o seu desenvolvimento normal, portanto, de modo a atender essa criança em suas necessidades de movimento. Sua base teórica é essencialmente a psicologia do desenvolvimento e da aprendizagem [...] (BRACHT, 1999, p. 78).

Evidencias apontam que nos anos 80 em Caxias do Sul, o ensino da Educação Física também foi desenvolvido pelos preceitos da psicomotricidade, no entanto, outra modalidade que ganhou espaço nas escolas primárias foi o futebol de salão ${ }^{12}$, mesmo que não esteja nas legislações como um componente curricular obrigatório. Isso ocorreu em função dos espaços físicos destinados às aulas de Educação Física, pelas condições climáticas e também pelo número de alunos necessários à formação das equipes (FONSECA, 2010). Para o autor, nos anos 80, ocorreu a perpetuação dos esportes sem caracterização competitivista e o crescimento do atletismo, visto a baixa necessidade de materiais e também pela possibilidade de apreensão de uma vasta experiência motora aos alunos.

Outro ponto destacado no município refere-se à construção de novos prédios para os grupos escolares ou a melhoria dos existentes. Assim, as escolas receberam novos e/ou melhores espaços físicos, algumas com quadras adequadas para as aulas de Educação Física, outras, caso da EGG, apenas um pátio coberto com pavimento de concreto. Também foram

$11 \mathrm{O}$ conceito de psicomotricidade "[...] refere-se ao movimento da criança com o ato de aprender, com os processos cognitivos, afetivos e psicomotores, ou seja, busca-se garantir a formação integral do aluno" (PELEGRINI, 2008, p. 43-44).

${ }^{12} \mathrm{O}$ futebol de salão, conhecido atualmente como futsal, é semelhante ao futebol, porém jogado com cinco jogadores para cada equipe numa quadra geralmente de 20x40 metros com piso de madeira ou concreto. Teve sua origem no Uruguai na década de 30, mas foi no Brasil, nas décadas seguintes, que ele recebeu o maior impulso para o seu desenvolvimento (FONSECA et al., 2011). 
ampliados os materiais didáticos ofertados para as professoras, o que possibilitou a organização e inserção de novas possibilidades educativas nas aulas (GIACOMONI, 2018).

Expostos os dois contextos educacionais, aos quais a Educação Física primária esteve atrelada, cabe ressaltar também que as professoras Jacira e Jaqueline tiveram trajetórias educacionais com uma formação generalista referente a este campo. Desse modo, no município de Caxias do Sul, assim como em grande parte do país, as professoras que foram formadas nas escolas normais e/ou magistério e atuavam no ensino primário, inclusive na EGG,

[...] receberam um treinamento mínimo em relação à área, pois contaram em seus estudos com pouca aprendizagem sobre a questão da Educação Física. O único assunto relacionado ao ensino de Educação Física foi a chamada Didática da Educação Física, onde futuros professores conheciam os conteúdos que deveriam desenvolver em suas aulas. Assim, houve muito pouca formação inicial de professores que ensinou nas escolas primárias municipais (FONSECA, 2010, p. 540).

Portanto, existiram diferenças nas maneiras de organizar as aulas e as práticas de Educação Física primária nas décadas de 70 e 80. Durante os anos 70, em âmbito nacional, as aulas eram organizadas e desenvolvidas com atenção direcionada aos esportes, principalmente futebol e voleibol, no entanto, no âmbito municipal as professoras utilizavam as brincadeiras e os esportes de modo adaptado sem o viés competitivista e tecnicista. Nos anos 80, as novas abordagens educativas buscaram uma ampliação pedagógica quanto as aulas de Educação Física, o que foi possível devido aos melhores espaços físicos e a ampliação dos materiais didáticos, proporcionando a inclusão da psicomotricidade na organização das aulas de Educação Física. Porém, os esportes mantiveram seu papel de destaque, e as professoras primárias continuaram recebendo uma formação incompleta no campo da Educação Física.

\section{Memórias das aulas e práticas de educação física na Escola Giuseppe Garibaldi}

Esta seção pretende recompor uma das possíveis versões históricas da Educação Física no ensino primário da EGG, ao direcionar a atenção para as aulas e práticas, organizadas e desenvolvidas pelas professoras Jacira e Jaqueline. Apesar dos contextos sociais, políticos e educacionais, ressaltamos que as memórias das professoras sobre as suas aulas e práticas de Educação Física na EGG evidenciaram singularidades e especificidades quando comparadas ao âmbito nacional.

Para compreender esses processos é necessário reiterar que as professoras Jacira e Jaqueline não possuíam uma formação específica na área, o que pode ter restringido as possibilidades práticas aos saberes ligados às trocas de informações com outras professoras, leituras de livros e revistas e/ou cursos realizados. Além disso, os espaços escolares da EGG, tanto no prédio antigo, quanto no novo, não proporcionavam situações favoráveis ao desenvolvimento das aulas. Agregado a este fato, ainda conviviam com a escassez de materiais didáticos (JACIRA, 2017; JAQUELINE, 2017).

A EGG, inaugurada em 1974, permaneceu apenas dois anos na residência alugada do Sr. João Neves. O prédio era de alvenaria e as repartições de madeira, possuía três salas de aula, atendia cerca de 90 alunos nos turnos da manhã e tarde. Os espaços escolares destinados às aulas de Educação Física eram num pátio de brita ou na própria sala de aula, e os materiais compostos por poucas bolas e cordas (EMEFGG, 1974; JACIRA, 2017). De acordo com Gatti Júnior (2000), os espaços escolares não são locais neutros, pois são formados pelos alunos, professores, funcionários, objetos e materiais, que possuem inter-relações, vínculos e sentidos que são empregados por esses sujeitos nesses espaços, permitindo possibilidades ou limites para os processos de escolarização. 
Nessas perspectivas, as aulas de Educação Física começam a ser orientadas pela diretora e também professora Jacira Koff Saraiva no ano de 1974, ao repassar orientações básicas de como organizar estas aulas. Basicamente, Jacira (2017) menciona em sua narrativa que "[...] $a$ Prefeitura cedia os livros conforme a série, nós tínhamos os livros que a gente seguia [...]". Segundo Luckesi (1994), a narrativa exposta possui características de um planejamento tecnicista de ensino, ao vincular as professoras como transmissoras do conhecimento, assim, os alunos pouco interagiam e atuavam de maneira crítica em sala de aula.

Conforme Jacira (2017), a maior parte das aulas ministradas pelas professoras primárias eram direcionadas por brincadeiras orientadas ou livres, e quando havia possibilidades de utilizar o pátio de brita, eram preferidos os esportes. Eventualmente, existiam aulas estruturadas com planos de aula organizados, com conteúdos vinculados às ginásticas ou atletismo. Reitera que o propósito dessas aulas não era a formação de atletas, de exclusão dos alunos que não conseguiam realizar as atividades, e que também não havia distinções entre gêneros, pois todos realizavam as mesmas atividades, cada um a seu tempo e maneira.

Assim, compreendemos que o competitivismo não foi cogitado, visto que a Educação Física "[...] simplesmente fazia parte, porque se achava bom e é, naturalmente, atividade física é extremamente importante, mas nunca foi vinculado a uma cobrança enorme [...]", (JACIRA, 2017). As aulas possuíam frequência semanal de uma a duas vezes, realizadas no pátio de brita quando o tempo era favorável ou no interior da sala de aula quando estava chovendo ou fazia muito frio. Além disso, indícios apontam que era realizada cerca de uma aula mensal estruturada com a composição de um plano de aula e objetivo específico, definidos pelas professoras primárias (JACIRA, 2017).

Faria Filho e Vidal (2000) ressaltam que a adaptação e improvisação dos espaços escolares se acentuaram nos anos 50 e 60, pois o governo buscou simplificar e economizar nas construções dos prédios escolares, indicando alterações nas concepções educativas sobre estes espaços. Assim, os espaços escolares transformaram-se em ambientes funcionais, pensados e arquitetados para uma educação rápida e eficiente, que além da sala de aula possuía locais específicos para acolher os docentes e os funcionários.

Ao avançar para a década de 80, a EGG passa a ocupar outro espaço físico, inaugurado em 14 de novembro de 1976, próximo às suas antigas instalações. Este prédio construído em alvenaria é composto por dois andares e salas de aula mais amplas, arejadas e iluminadas. Todavia, ainda não existem quadras específicas destinadas à Educação Física, e como recurso, as professoras passam a utilizar o pátio coberto com piso de concreto para desenvolver suas aulas (EMEFGG, 1974; JAQUELINE, 2017).

Da mesma forma como retrata Jacira em sua narrativa, Jaqueline (2017) rememora que também existiam os livros didáticos cedidos pela Prefeitura, no entanto, possuíam uma maior liberdade de organização e atuação em suas aulas. Grande parte dessas aulas era realizada no pátio coberto, independente do clima e com frequência semanal que variava de duas a três vezes. Segundo Ribeiro (2004), os novos espaços escolares deveriam caracterizar-se por locais agradáveis aos alunos e professores, pois estes ambientes podem ser limitadores ou facilitadores dos processos de escolarização, bem como das relações sociais e culturais entre os sujeitos que o permeiam.

As práticas esportivas ainda possuem protagonismo frente as demais, principalmente pelo futebol e voleibol, também de forma adaptada, e sem a caracterização competitiva e tecnicista. Por outro lado, os esportes também foram desenvolvidos quando as professoras não desejavam ministrar a aula de Educação Física, e assim levavam os alunos para o pátio da escola "[...] para brincar, digamos um recreio prolongado, então isso não ajudou a desenvolver fisicamente os alunos" (JAQUELINE, 2017). Para Silva (2010), o espaço do recreio constitui-se como um momento informal para práticas vinculadas à Educação Física, uma vez que não possuem intervenção direta das professoras. 
No entanto, algumas mudanças significativas são evidenciadas quanto à organização e planejamento das aulas de Educação Física, no momento que as professoras primárias começam a se preocupar com práticas que envolviam os alunos com a "[...] psicomotricidade ampla para ele desenvolver bem para trabalhar a fina na sala de aula. Então a gente fazia as letras no chão e eles passavam por cima, não gostavam né, eles queriam brincar, correr" (JAQUELINE, 2017).

Por meio da narrativa de Jaqueline, foram percebidos indicadores de uma preocupação em suas aulas com os componentes das coordenações motoras ampla e fina. Compreendemos que essas práticas de Educação Física foram direcionadas a esses alunos em decorrência da sua formação docente, por entendê-la como um campo que possibilita o desenvolvimento dos processos de escolarização de forma interdisciplinar, além de favorecer os aspectos físicos, cognitivos, afetivosemocionais e também contribuir para a formação da personalidade (FONSECA, 1988).

Inseridas nas aulas de Educação Física, também existiam as brincadeiras, direcionadas pela professora regente ${ }^{13}$ da turma ou de forma livre, entendidas como um momento de "liberação de energia" dos alunos. Apesar dos achados de Fonseca (2010), não encontramos evidências da prática do futebol de salão na EGG. Para Bracht (1999), alguns dos fatores expostos levaram à Educação Física escolar a uma falta de identidade neste período, gerando conflitos sobre suas finalidades educativas, e ameaçando sua presença nas escolas, visto que não possuía um corpo teórico próprio e foram divulgados muitos conhecimentos de forma incoerente sobre a área.

Desta forma, independente das prescrições legais, entendemos que as professoras possuíam consciência sobre a importância destas práticas para a formação dos alunos em seus mais variados contextos, e não somente pelos aspectos físicos, mas para a construção de um "[...] conjunto de saberes e fazeres, de valores e comportamentos que configuram sentidos e significados vinculados às práticas corporais tematizadas e construídas por essa prática social no âmbito da instituição escolar" (RODRIGUES; BRACHT, 2010, p. 94).

A partir do explicitado, percebemos que as professoras Jacira Koff Saraiva e Jaqueline Gedoz Vita organizavam e desenvolviam suas aulas de Educação Física pelas brincadeiras visando ao lazer, aos esportes adaptados sem viés competitivista e eram limitadas pela não formação na área, pelos espaços escolares e pelos materiais didáticos of erecidos. Mesmo assim, nota-se um esforço docente para seguir os planos propostos pela legislação, encontrar soluções educativas, tanto nos espaços, quanto nos materiais para um desenvolvimento satisfatório das aulas de Educação Física.

\section{Considerações finais}

Pesquisas no campo da história da educação que relacionam âmbitos e contextos distintos nos faz (re)pensar sobre as semelhanças, diferenças, permanências, singularidades e suas relações com os processos de ensino da Educação Física nas séries primárias. Dessa forma, a partir das memórias das professoras Jacira Koff Saraiva e Jaqueline Gedoz Vita, foi possível conhecer, compreender e analisar um pouco mais sobre as formas de organização das aulas e das práticas de Educação Física no ensino primário na EGG no município de Caxias do Sul, durante um período do regime civil militar.

As narrativas das professoras Jacira Koff Saraiva e Jaqueline Gedoz Vita sobre os anos de 1974 a 1985 evidenciam que as aulas de Educação Física no ensino primário na EGG eram organizadas e desenvolvidas a partir de uma proposta pedagógica, pois seguiam os livros do município ou seus próprios conhecimentos sobre a temática, mas não aos anseios nacionalistas. Apesar de suas concepções formativas distintas e os dois espaços e tempos

\footnotetext{
${ }^{13}$ Regente da turma ou regente de classe "é o professor unidocente ou o titular de uma disciplina específica" (SILVA JR.; RANGEL, 2011, p. 30).
} 
escolares, muitas memórias evidenciadas pelas entrevistadas foram semelhantes quanto às aulas e as práticas de Educação Física.

Quanto aos espaços físicos destinados à Educação Física, ressaltamos que em ambos os prédios escolares não existiam locais adequados designados para essas aulas. Assim, nas antigas instalações escolares da EGG, a professora Jacira possuía duas opções: o pátio de chão batido coberto com britas ou a pequena sala de aula modelada pelos próprios moradores do bairro. No novo prédio, também não existiam quadras específicas para a Educação Física, porém a professora Jaqueline possuía duas vantagens em relação ao antigo espaço: um pátio coberto e com piso de concreto, além de salas de aulas amplas, bem arejadas e iluminadas.

A escola também possuía carências de materiais didáticos para o desenvolvimento das aulas de Educação Física, pois contavam com apenas algumas bolas, bambolês, cordas e os demais materiais sempre eram adaptados como: garrafas plásticas, latas de metal, cabos de vassoura dentre outros. Referenciam que não eram obrigadas pelos seus superiores, tanto da escola, como também da Secretaria de Educação, a lecionar a disciplina de Educação Física nas séries primárias, mas no entendimento delas consideravam importante para desenvolvimento dos seus alunos.

Analisando as narrativas, o período de formação das professoras e também de suas formações subsequentes, podemos pressupor que: Jacira possuiu uma formação tecnicista que acabou não se refletindo nas suas práticas, visto a opção pelas brincadeiras, pelos esportes de forma adaptada, talvez justificados pelas limitações dos espaços e materiais. Já a professora Jaqueline possuiu influências diretas do campo da disciplina escolar de Educação Física no magistério, dos cursos realizados, bem como das trocas sociais e didáticas realizadas entre as escolas e entre professores, o que proporcionou a inserção de novas possibilidades educativas aos alunos. Ressaltamos que ambas as professoras viveram em contextos, espaços e tempos distintos na EGG, o que também influenciou as formas de organizar suas aulas e práticas.

Portanto, apesar das dificuldades encontradas pelas professoras primárias da EGG, consideramos que os alunos obtiveram um aproveitamento satisfatório das aulas de Educação Física dentro das possibilidades apresentadas naquele período. Os espaços físicos e os materiais didáticos foram limitadores dos processos educativos, porém superados pela intensa iniciativa das professoras na busca de metodologias de trabalho para suas aulas de Educação Física, além da troca de materiais didáticos, pedagógicos para constituição destas aulas entre as escolas e também entre estas professoras primárias.

\section{Referências}

ALBERTI, Verena. Manual de história oral. 3 ed. Rio de Janeiro: Editora FGV, 2013.

BRASIL. Lei $\mathbf{n}^{0}$ 5.692. Fixa Diretrizes e Bases para o ensino de $1^{\circ}$ e $2^{\circ}$ graus, e dá outras providências. Brasil. 11 ago. 1971a.

BRASIL. Decreto $\mathbf{n}^{0}$ 69.450. Regulamenta o artigo 22 da Lei número 4.024, de 20 de dezembro de 1961, e alínea c do artigo 40 da Lei 5.540, de 28 de novembro de 1968 e dá outras providências. Brasil. 1 nov. 1971b.

BRASIL. Resolução n⿳ 510. Resolução dispõe sobre as normas aplicáveis a pesquisas em Ciências Humanas e Sociais. Brasil. 7 abr. 2016.

BRACHT, Valter. A constituição das teorias pedagógicas da Educação Física. Cadernos Cedes. Campinas, n. 48, p. 69-88, ago. 1999. https://doi.org/10.1590/S0101-32621999000100005 
BENCOSTTA, Marcus Levy Albino. História da educação, arquitetura e espaço escolar. São Paulo: Cortez Editora, 2005.

BUFFA, Ester. História e filosofia das instituições escolares. In: ARAÚJO, José Carlos Souza; GATTI JUNIOR, Décio (Orgs.). Novos temas em história da educação brasileira: instituições escolares e educação na imprensa. Campinas: Editora Autores Associados, 2002. p. 25-38.

BURKE, Peter. O que é História Cultural? Rio de Janeiro: Zahar, 2008.

CAXIAS DO SUL. Anais - 55 ${ }^{\mathbf{a}}$ Sessão Ordinária do $\mathbf{1}^{\mathbf{0}}$ Período Legislativo da VIII Legislatura. Caxias do Sul-RS, Centro de Memória da Câmara de Vereadores de Caxias do Sul, 17 de outubro de 1977.

CAXIAS DO SUL. Secretaria Municipal de Educação e Cultura; LAZZAROTTO, Valentim Angelo; VALENTIM, Joceli (Coord.). Vilas \& bairros: a história contada pela comunidade. Caxias do Sul, RS: SMEC, 1986.

CAXIAS DO SUL. Mapa do município - escala 1/10.000. Disponível em: http://www.caxias.rs.gov.br/_uploads/planejamento/sui/sui_mapa_municipio.pdf. Acesso em: 22 maio 2017.

CHARTIER, Roger. A história cultural: entre práticas e representações. Tradução de Maria Manuela Galhardo. Lisboa: Difusão Editora, 1988.

DALLA VECCHIA, Marisa Virgínia Formolo; HERÉDIA, Vania Beatriz Merlotti; RAMOS, Felisbela. Retratos de um saber: 100 anos de história da rede municipal de ensino em Caxias do Sul. 2. ed. Porto Alegre: EST, 1998.

DALLA VECCHIA, Marisa Virgínia Formolo; HERÉDIA, Vania Beatriz Merlotti; RAMOS, Felisbela. Contradições no sistema de educação: uma releitura acerca da expansão da rede municipal de ensino em Caxias do Sul. MÉTIS: história \& cultura. Caxias do Sul, v. 7, n. 14, p. 21-36, jul./dez. 2008.

EMEFGG. Caderno de Atas de Reuniões com Professores (1974 - 1976). Caxias do Sul-RS, Cristo Redentor, 1974.

FARIA FILHO, Luciano Mendes de; VIDAL, Diana Gonçalves. Os tempos e os espaços escolares no processo de institucionalização da escola primária no Brasil. Revista Brasileira de Educação. Rio de Janeiro, n. 14, p. 20-34, maio/jun./jul./ago. 2000.

FERNANDES, Ananda Simões. Quando o inimigo ultrapassa a fronteira: as conexões repressivas entre a ditadura civil-militar brasileira e o Uruguai (1964-1973). 2009. 275f. Dissertação (Mestrado em História) - Programa de Pós-Graduação em História, Instituto de Filosofia e Ciências Humanas, Universidade Federal do Rio Grande do Sul, UFRGS, Porto Alegre, 2009.

FERREIRA, Marieta de Moraes; AMADO, Janaína (Orgs.). Usos \& abusos da história oral. 7. ed. Rio de Janeiro: Editora FGV, 2005.

FONSECA, Gerard Maurício Martins. De la gimnástica a la deportivización: la Historia de la Educación Física en las escuelas municipales de Caxias do Sul-Brasil. 2010. 594f. Tese (Doutorado) - Departamento De Educación Física, Deporte Y Motricidad Humana, Universidad Autónoma de Madrid, Madrid, 2010. 
FONSECA, Gerard Maurício Martins; GIACOMONI, Cristian; SONDA, Francesca Chaida; GIOTTO, Maria de Lourdes. A história do futebol de salão caxiense: as notícias da sua origem. Motriz: Revista de Educação Física. Rio Claro, v. 17, p. s349-s349, 2011.

FONSECA, Vitor da. Psicomotricidade. São Paulo: Martins Fontes, 1988.

FURLAN, Elisangela. Educação na década de 1970: formação sem informação. In: Jornada do HISTEDBR, 11, Cascavel. Anais da XI Jornada do HISTEDBR. Cascavel: Universidade Estadual do Oeste do Paraná, 2013. p. 1-12.

GATTI JR, Décio. Reflexões teóricas sobre a história das instituições educacionais. Revista Ícone. Uberlândia, v. 6, n. 2, p. 131-147, jul./dez. 2000.

GIACOMONI, Cristian. A Educação Física no ensino primário: memórias de professoras e alunos da Escola Giuseppe Garibaldi - Caxias do Sul/RS (1974-1989). 2018. 173 f. Dissertação (Mestrado em Educação) - Programa de Pós-Graduação em Educação, Universidade de Caxias do Sul, Caxias do Sul, 2018.

GIL, Natália; CALDEIRA, Sandra. Escola Isolada e Grupo Escolar: a variação das categorias estatísticas no discurso oficial do governo brasileiro e de Minas Gerais. Estatística e Sociedade. Porto Alegre, n. 1, p. 166-181, nov. 2011.

GRAZZIOTIN, Luciane Sgarbi Santos. Memórias recompondo tempos e espaços da educação - Bom Jesus/RS (1913-1963). 2008. 94f. Tese (Doutorado) - Programa de Pós-Graduação em Educação, Faculdade de Educação, Pontifícia Universidade Católica do Rio Grande do Sul, Porto Alegre, 2008.

HALBWACHS, Maurice. A memória coletiva. São Paulo: Centauro, 2006.

HOBSBAWM, Eric John. Sobre história: ensaios. São Paulo: Cia. das Letras, 1998.

IWAYA, Marilda. Palácio da instrução: representações sobre o Instituto de Educação do Paraná Professor Erasmo Pilotto (1940 - 1960). 148f. 2000. Dissertação (Mestrado) - Programa de Pósgraduação em Educação, Universidade Federal do Paraná, Curitiba, 2000.

JACIRA, Koff Saraiva. Entrevista oral sobre as práticas de Educação Física e os primeiros tempos da Escola Giuseppe Garibaldi. Entrevista concedida a Cristian Giacomoni. Caxias do Sul, 30 de set. de 2017. Entrevista.

JAQUELINE, Gedoz Vita. Entrevista oral sobre as práticas de Educação Física e os primeiros tempos da Escola Giuseppe Garibaldi. Entrevista concedida a Cristian Giacomoni. Caxias do Sul, 31 de mar. de 2017. Entrevista.

LOZANO, Jorge Eduardo Aceves. Prática e estilos de pesquisa na história oral contemporânea. In: FERREIRA, Marieta de Moraes; AMADO, Janaína (Orgs.). Usos \& abusos da história oral. 7. ed. Rio de Janeiro: Editora FGV, 2005. p. 15-25.

LUCHESE, Terciane Ângela. Modos de fazer história da educação: pensando a operação historiográfica em temas regionais. História da Educação. Porto Alegre, v. 18, n. 43, p. 145-161, mai./ago. 2014. https://doi.org/10.1590/S2236-34592014000200009 
LUCKESI, Cipriano Carlos. Filosofia da Educação. São Paulo: Cortez, 1994.

MACIEL, Marciani; COLLING, Juliane; JUNIOR, Luiz Martins; PAIN, Robson Olivino. Políticas educacionais na ditadura militar brasileira: entre o giz e o chumbo. In: Congresso IberoAmericano de Humanidades, Ciências e Educação, 2, 2016. Anais do II Congresso IberoAmericano de Humanidades, Ciências e Educação. Criciúma: Universidade do Extremo Sul Catarinense, v. 1, n. 1, p. 1-8, 2016. https://doi.org/10.18616/ce.v0i0.2952

MANZINI, Eduardo José. Uso da entrevista em dissertações e teses produzidas em um programa de pós-graduação em educação. Revista Percurso. Maringá, v. 4, n. 2, p. 149-171, 2012.

MENDONÇA, Daniel de. A vitória de Tancredo Neves no Colégio Eleitoral e a posição política dos semanários Veja e Isto É. ALCEU. Rio de Janeiro, v. 5, n. 10, p. 164-185, jan./jun. 2005.

MIGNOT, Ana Chrystina Venancio; CUNHA, Maria Teresa Santos. Razões para guardar: a escrita ordinária em arquivos de professores/as. Revista Educação em Questão. Natal, v. 25, n. 11, p. 40-61, jan./abr. 2006.

NÓVOA, Antonio. Os professores e a sua formação. Tradução de Graça Cunha, Cândida Hespanha e Conceição Afonso. Lisboa: Dom Quixote, 1992.

OLIVEIRA, Marcus Aurélio Taborda de. A Revista Brasileira de Educação Física e Desportos (1968-1984) e a experiência cotidiana de professores da Rede Municipal de Ensino de Curitiba: entre a adesão e a resistência. 2001. 398 f. Tese (Doutorado em Educação) - Pontifícia Universidade Católica de São Paulo - PUC, São Paulo, 2001.

OLIVEIRA, Marcus Aurélio Taborda de. Educação Física escolar e ditadura militar no Brasil (1968-1984): história e historiografia. Educação e Pesquisa. São Paulo, v. 28, n. 1, p. 51-75, jan./jun. 2002. https://doi.org/10.1590/S1517-97022002000100004

PELEGRINI, Tiago Boeira. A Educação Física na perspectiva de uma pedagogia crítica transformadora. 2008. 59f. Monografia (Especialização) - Curso de Pós- Graduação em Didática e Metodologia do Ensino Superior, Universidade do Extremo Sul Catarinense, Criciúma, 2008.

RIBEIRO, Solange Lucas. Espaço escolar: um elemento (in)visível no currículo. Sitientibus. Feira de Santana, n. 31, p. 103-118, jul./dez. 2004.

RICCI, Rudá. Vinte anos de reformas educacionais. Revista Iberoamericana de Educación. Madrid, n. 31, p. 91-120, jan./abr. 2003.

RIO GRANDE DO SUL. Fundação Estadual de Economia e Estatística. Divisão Geopolítica do Estado do Rio Grande do Sul. Disponível em: https://www.fee.rs.gov.br/perfilsocioeconomico/estado/divisao-geopolitica-do-rs/ Acesso em: 15 abr. 2019.

RODRIGUES, Leonardo Lima; BRACHT, Valter. A cultura da Educação Física. Revista Brasileira de Ciências do Esporte. Campinas, v. 32, n. 1, p. 93-107, set. 2010. https://doi.org/10.1590/S0101-32892010000400007

SANTOS, José Carlos Eustáquio. Ginástica geral: elaboração de coreografias organização de festivais. Jundiaí: Fontoura, 2001. 
SILVA, Alan Marques da. O brincar no contexto escolar: significados das brincadeiras realizadas em aulas de educação física e no recreio. 2010. 157f. Dissertação (Mestrado) - Pós-graduação da Faculdade de Educação Física, Universidade Estadual de Campinas, Campinas, 2010.

SILVA, Hilanna Mayara Lessa; BEZERRA, Ada Augusta Celestino; SANTOS, Blenda Joyce dos. Caracterizando a década de 1980 no Brasil: em busca da identidade da Educação Física. In: Encontro Internacional de Professores, 10, Aracaju, 2017. Anais do $\mathbf{1 0}^{\mathbf{0}}$ Encontro Internacional de Professores. Aracaju, v. 10, n. 1, 2017. Disponível em: < https://docplayer.com.br/63419997Caracterizando-a-decada-de- $\quad$ 1980-no-brasil-em-busca-da-identidade-da-educacao-fisica.html $>$. Acesso em: 3 abr. 2018.

SILVA JR., Celestino Alves da; RANGEL, Mary (Orgs.). Nove olhares sobre a supervisão. 16. ed. Campinas, SP: Papirus, 2011.

SOARES, Carmen Lúcia; TAFFAREL, Celi; VARJAL, Elizabeth; CASTELLANI FILHO, Lino; ESCOBAR, Micheli Ortega; BRACHT, Valter. Metodologia do Ensino da Educação Física. São Paulo: Cortez, 2009.

SOUZA, Rosa Fátima de. Templos de civilização: a implantação da escola primária graduada no Estado de São Paulo (1890-1910). São Paulo: UNESP, 1998.

SOUZA, José Edimar de. Trajetória de professores de classes multisseriadas: memórias do ensino rural em Novo Hamburgo/RS (1940 a 2009). 2011. 346f. Dissertação (Mestrado em Educação) - Programa de Pós-Graduação em Educação, Universidade do Vale do Rio dos Sinos Unisinos, São Leopoldo, 2011.

SOUZA, José Edimar de. As escolas isoladas: práticas e culturas escolares no meio rural de Lomba Grande/RS (1940 a 1952). 2015. 295f. Tese (Doutorado em Educação) - Programa de Pós-Graduação em Educação, Universidade do Vale do Rio dos Sinos - Unisinos, São Leopoldo, 2015.

STEPHANOU, Maria; BASTOS, Maria Helena Camara. História, memória e história da educação. In: STEPHANOU, Maria; BASTOS, Maria Helena Camara (Orgs.). Histórias e memórias da educação no Brasil, Vol. III: século XX. Petrópolis: Vozes, 2011. p. 416-429.

VIDAL, Diana Gonçalves; SCHWARTZ, Cleonara Maria. Sobre cultura escolar e história da educação: questões para debate. In: VIDAL, Diana Gonçalves; SCHWARTZ, Cleonara Maria (Orgs.). História das culturas escolares no Brasil. Vitória: EDUFES, 2010. p. 13- 36.

ZIENTARSKI, Clarice; PEREIRA, Sueli Menezes. Os caminhos para a democratização da educação no Brasil: qual o papel dos educadores neste processo? Revista HISTEDBR On-line. Campinas, n. 34, p. 154-166, jun. 2009. https://doi.org/10.20396/rho.v9i34.8639585 